\title{
Synthesis of ZSM-5 coatings on stainless steel grids and their catalytic performance for partial oxidation of benzene by $\mathrm{N}_{2} \mathrm{O}$
}

\author{
B. Louis, P. Reuse, L. Kiwi-Minsker*, A. Renken \\ Institute of Chemical Engineering, Swiss Federal Institute of Technology, CH-1015 Lausanne, Switzerland
}

Received 31 May 2000; received in revised form 5 September 2000; accepted 5 September 2000

\begin{abstract}
The one step hydroxylation of benzene has been performed over structured catalytic bed made of ZSM-5 coatings grown by hydrothermal synthesis on stainless steel grids. The catalysts demonstrated a $97 \%$ selectivity towards phenol formation at benzene conversion of $11 \%$. In addition of achieving the same reactivity as over the traditional zeolitic fixed beds, these new catalytic packings present several advantages gained from the special arrangement of the catalytic bed like low pressure drop, improved heat and mass transfer, and controlled hydrodynamics. (C) 2001 Elsevier Science B.V. All rights reserved.
\end{abstract}

Keywords: ZSM-5 zeolite; Coatings; Stainless steel; Structured catalyst; Benzene hydroxylation; Nitrous oxide

\section{Introduction}

In heterogeneous catalysis, it is recognised that a catalyst is not a new chemical compound, but a finely designed material. Chemical composition can efficiently work only in combination with well-organised micro- and macro-structure of the material. Moreover, the texture and mechanical properties of the catalyst influence strongly the appropriate choice of chemical reactor and finally, the technology employed. This in turn determines the economic feasibility of a process.

Zeolites are known to possess a microporous structure with well-defined pore form and size. Moreover, the zeolites can be loaded via ion-exchange by cations to meet the requirements of a specific chemical transformation. Therefore, a control of chemical composition and of microstructure is insured by zeolite

\footnotetext{
${ }^{*}$ Corresponding author.

E-mail address: lioubov.kiwi-minsker@epfl.ch (L. Kiwi-Minsker).
}

synthesis. In contrast, the macrostructure of zeolite catalyst packings is largely undefined. Zeolites are used in catalytic fixed beds, randomly packed by powdered micro-granules or extrudated pellets with a few millimetres in size. The main disadvantages of fixed beds are:

- high pressure drop during the gas passage through the catalytic bed;

- limited heat and mass transfers;

- flow maldistribution causing loss of selectivity;

- high susceptibility to fouling by dust.

During the last decades there has been a growing interest in catalytic reactor engineering based on structured catalytic beds. This is a valuable alternative to conventional fixed beds and slurry catalytic reactors [1]. The main disadvantages of the traditional zeolite fixed beds could be avoided by the use of structured catalyst packing [2]. These packings are prepared via zeolitic coatings of metal grids. Despite 
the increasing interest to structured catalytic beds, only a few practical applications have been reported consisting of structured zeolitic packings [3].

A one-step oxidation of benzene by nitrous oxide is an attractive way of phenol production and various catalysts based on metal oxides have been used for this process [4-13]. The MFI type zeolites have been reported as the most efficient catalyst with selectivity as high as $95 \%$ towards phenol formation at appreciable conversion [6-10].

The objectives of this study were to investigate HZSM-5 coatings grown on stainless steel grids for benzene oxidation by $\mathrm{N}_{2} \mathrm{O}$ and to compare their performance with unsupported HZSM-5 catalyst. The influence of the $\mathrm{N}_{2} \mathrm{O} / \mathrm{C}_{6} \mathrm{H}_{6}$ ratio on the catalytic activity/selectivity has also been investigated. The HZSM-5 crystalline coatings were characterised via BET, X-ray diffraction (ZRD), and scanning electron microscopy (SEM) methods.

\section{Experimental}

\subsection{Catalyst preparation}

Stainless steel grid (AISI 316, wire diameter of $250 \mu \mathrm{m}$ and mesh size of $800 \mu \mathrm{m}$ ) was used as a starting material for the preparation of the structured catalytic bed with zeolite coatings. The structured support packing was arranged by a superposition of 15 plates $\left(9 \mathrm{~cm}^{2}\right)$ separated from each other by steel rings of $4 \mathrm{~mm}$ length. The whole support packing was pre-treated in boiling toluene during $2 \mathrm{~h}$ and in a $15 \%$ hydrochloric acid solution during $20 \mathrm{~min}$ in order to remove organic and inorganic contaminations. Afterwards, the packing was rinsed in distilled water under ultrasonic treatment. This procedure is known to create defects on the metal surface, which become crystallisation centres during the synthesis of the zeolite coating $[14,15]$.

The zeolite synthesis mixture was prepared by adding at room temperature sodium aluminate (52.5 wt.\% $\mathrm{NaAlO}_{2}$, Riedel-de Haën), sodium chloride (99.5 wt.\%, Fluka, Chemika), tetrapropylammonium hydroxide (20 wt.\% in water, Fluka, Chemika) in demineralised water. Then, the tetraethyl orthosilicate (TEOS, 98\%, Merck-Suchardt) was introduced under vigorous stirring. The molar ratio was as follows: TPA-OH:Si(OEt $)_{4}: \mathrm{NaCl}: \mathrm{NaAlO}_{2}: \mathrm{H}_{2} \mathrm{O}=$ 2.16:5.62:3.43:0.13:1000. Ageing and homogenisation of the mixture were performed during $2-3 \mathrm{~h}$. The gel was afterwards poured in a $250 \mathrm{ml}$ Teflon-lined autoclave containing the vertically positioned catalytic support packing. Before the synthesis the support packing was impregnated by a $0.1 \mathrm{M}$ solution of the tetrapropylammonium bromide (organic template) to direct the zeolite crystallisation onto the support [16]. The temperature was increased within $1 \mathrm{~h}$ up to $444 \mathrm{~K}$ and the zeolite synthesis took place during $40 \mathrm{~h}$ under autogeneous pressure. The synthesis procedure was repeated three times with a fresh solution to enhance the weight of zeolite coating. Finally, the packing was kept in an ultrasonic bath $(45 \mathrm{kHz})$ for $20 \mathrm{~min}$ to remove loosely attached crystals and dried overnight at $400 \mathrm{~K}$. The three-step synthesis was followed by a calcination over a night at $773 \mathrm{~K}$ in air. The MFI structure was obtained in sodium form and was exchanged three times with ammonium chloride $(0.1 \mathrm{M})$ at $353 \mathrm{~K}$, then calcined at $773 \mathrm{~K}$ during $5 \mathrm{~h}$ in air resulting in H-ZSM5.

Zeolite crystals deposed on the bottom of the autoclave were collected, exchanged and calcined in the same manner as the structured packing. Commercial H-MFI-90 (1/16 in. extrusions, Süd-Chemie) was used as received. Iron content as measured by atomic absorption spectroscopy was found to be less than $0.1 \mathrm{wt} . \%$.

The coverage of a packing was determined as the mass of zeolite coated referred to the geometrical surface of the support. The ratio between the amount of silicon incorporated in the zeolite matrix and the initial amount of silicon in the synthetic mixture gives the yield of the zeolite coating.

\subsection{Characterisation}

Specific surface areas of the catalysts used were determined by nitrogen adsorption $(77 \mathrm{~K})$ employing BET method via Sorptomatic 1900 (Carlo-Erba). XRD patterns of powdered catalysts were carried out on a Siemens D5000 $(\theta / 2 \theta)$ diffractometer with $\mathrm{Cu} \mathrm{K \alpha}$ monochromatic radiation $(\lambda=1.5406 \AA)$. The surface morphology and the thickness of the crystalline layer (zeolite coating) were studied by SEM on a JEOL JSM $6300 \mathrm{~F}$ apparatus. The $\mathrm{Si} / \mathrm{Al}$ ratio of the crystals was determined by energy dispersive X-ray (EDX) analysis coupled with the SEM chamber. 


\subsection{Set-up and procedure}

The catalytic reaction was carried out at $623 \mathrm{~K}$ and atmospheric pressure in a stainless steel tubular reactor. The structured catalyst (in the form described above and containing totally $1.45 \mathrm{~g}$ of HZSM-5 on the metal grid) was placed into the reactor and activated at $823 \mathrm{~K}$ during $1 \mathrm{~h}$ in nitrogen flow. The reaction mixture contained $3.8-16.4 \mathrm{~mol} \%$ of benzene and 0.4-16.7 mol\% of $\mathrm{N}_{2} \mathrm{O}$; nitrogen was used as diluant. The total flow was set to $60 \mathrm{STP} \mathrm{ml} \mathrm{min}^{-1}$. Aromatics were analysed by GC on-line (Shimadzu GC-14A, $30 \mathrm{~m}$ HP-5, FID). The $\mathrm{CO}_{2}$ formation was monitored by IR analyser (Siemens Ultramat-22P). By control experiments it was verified that the support alone was not active for the reaction.

The randomly packed fixed-bed was made by placing $10 \mathrm{~g}$ of the commercial catalyst H-MFI-90 or the powdered 'home-made' HZSM-5 in the middle part of the reactor between the two zones with glass beads. A considerable loss of activity during the reaction was observed due to catalyst coking. Therefore, the conversion and yield were measured between 50 and $150 \mathrm{~min}$ on stream, where the change in activity could be neglected. The catalyst regeneration was performed over a night under flow of air at $773 \mathrm{~K}$ and the initial activity could be restored. The reaction conversion was calculated from the quantity of the reacted benzene. The selectivity towards phenol was defined as the molar ratio of the phenol obtained to the benzene converted.

\section{Results}

\subsection{Zeolite coating}

Fig. 1 shows the yield of the zeolite coating and the support coverage in the three steps of synthesis. It is seen that during the first step only a $10 \%$ yield was obtained, while the second and the third steps gave an yield of $25 \%$. This fact indicates that the first zeolite layer attached directly onto the metal surface is the most difficult to create and it acts as a seeding for further crystallisation. A total coverage of about $95 \mathrm{~g}_{\mathrm{ZSM}-5} \mathrm{~m}^{-2}$ was obtained after three-steps coating procedure. These results correspond to those obtained by Shan et al. [17] on metal foils. A further coating was found not reasonable for the grid geometry used in this study, since the void fraction decreased drastically leading to a high pressure drop during the passage of gas through the catalytic bed. The reproducibility of

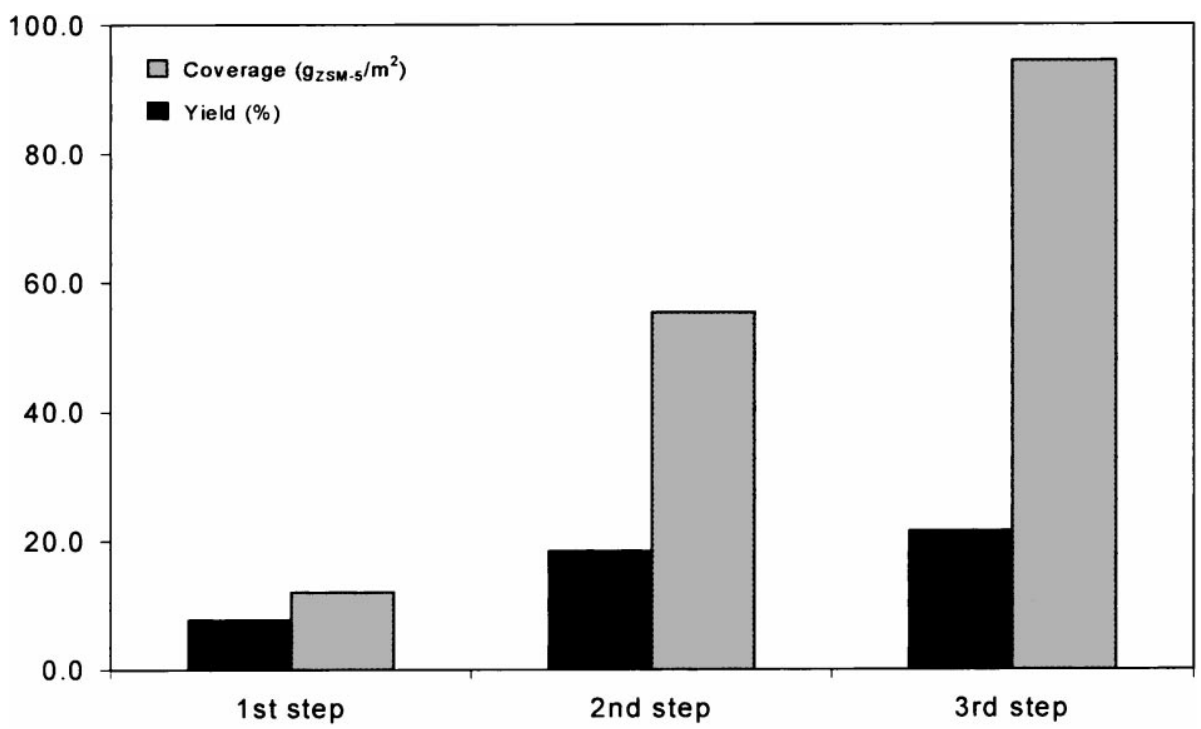

Fig. 1. Grid coverage and yields of the three steps synthesis of zeolite coatings. 

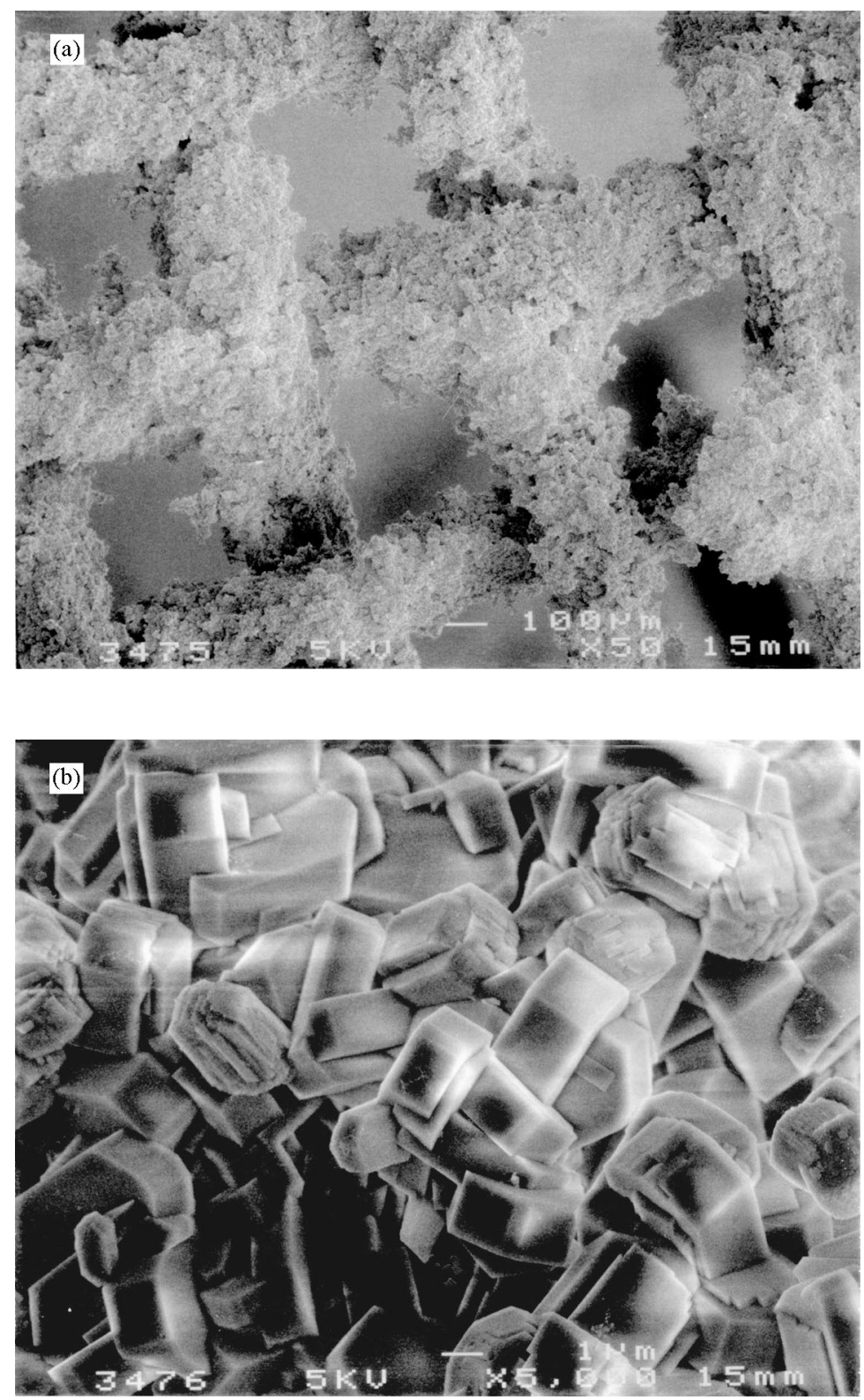

Fig. 2. SEM photographs of zeolite coatings: (a) the surface of the grid; (b) morphology of the zeolite crystals.

the synthesis yield was within $20 \%$. All the parameters were strictly controlled during the synthesis to obtain a reproducible deposition of ZSM-5.

Fig. 2a shows a SEM micrograph of the structured catalytic coating showing complete metal coverage. The thickness of the zeolite layer was estimated to be about $38 \mu \mathrm{m}$. Fig. 2 b shows the prismatic crystals morphology which is the character of ZSM-5. The elemental analysis of the zeolite layer studied by EDX analysis found a $\mathrm{Si} / \mathrm{Al}$ ratio of 65 . The XRD powder pattern of the crystals, which were scratched from the grid surface, confirmed the MFI structure (Fig. 3). The 


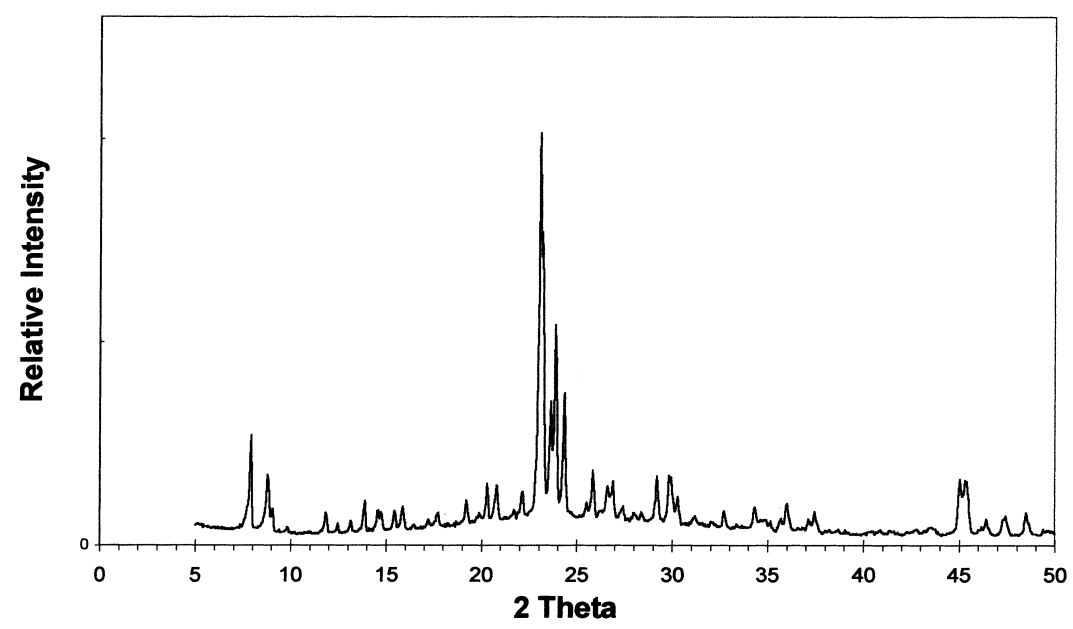

Fig. 3. X-ray powder diffraction pattern of zeolite ZSM-5 scratched from the stainless steel support.

BET surface area was $302 \mathrm{~m}^{2} \mathrm{gZSM}_{-5}{ }^{-1}$ with a total pore volume of $0.29 \mathrm{~cm}^{3} \mathrm{~g}_{\mathrm{ZSM}-5}{ }^{-1}$.

\subsection{Benzene hydroxylation}

Table 1 shows the dependence of conversion and selectivity on the benzene/nitrous oxide ratio and reactant concentrations. An excess of nitrous oxide is beneficial for benzene conversion as recently reported in the literature $[5,6]$. Nevertheless, the selectivity towards phenol goes down, which could be due to the consecutive total oxidation of benzene into carbon dioxide. In fact, when the concentration of $\mathrm{N}_{2} \mathrm{O}$ is low, the complete combustion of benzene is reduced; consequently the selectivity increases from 84 up to $97 \%$ in excess of benzene. It should be noticed that the phenol yield remains almost the same at different $\mathrm{N}_{2} \mathrm{O}$ concentrations. Despite the slight decrease of the conversion, it is advantageous to use excess of the aromatic substrate diminishing the separation problems and reducing the $\mathrm{CO}_{2}$ emission.

From the results presented in Table 1 it follows that the benzene conversion does not depend on the $\mathrm{N}_{2} \mathrm{O}$ concentration for the $\mathrm{C}_{6} \mathrm{H}_{6} / \mathrm{N}_{2} \mathrm{O}$ ratio $>0.8$. Therefore, a zero order with respect to $\mathrm{N}_{2} \mathrm{O}$ was assumed. The dependence between the benzene conversion and its gas-phase concentration is depicted in Fig. 4. A simple $n$th order irreversible reaction kinetics was chosen to describe the experimental data:

$r=k C_{\mathrm{B}}^{n}$

where $k$ represents the rate constant and $n$ the order

Table 1

The benzene conversion and selectivity towards phenol formation for different reactant concentrations and $\mathrm{C}_{6} \mathrm{H}_{6} / \mathrm{N}_{2} \mathrm{O}$ ratios

\begin{tabular}{lllll}
\hline $\mathrm{C}_{6} \mathrm{H}_{6} / \mathrm{N}_{2} \mathrm{O}$ & $\mathrm{C}_{6} \mathrm{H}_{6}\left(\mathrm{~mol} \mathrm{~m}^{-3}\right)$ & $\mathrm{N}_{2} \mathrm{O}\left(\mathrm{mol} \mathrm{m}^{-3}\right)$ & Benzene conversion $X$ & Selectivity to phenol $S$ \\
\hline 0.8 & 0.78 & 1.01 & 0.122 & 0.84 \\
2.0 & 0.78 & 0.39 & 0.119 & 0.93 \\
4.0 & 0.78 & 0.20 & 0.114 & 0.97 \\
0.8 & 0.66 & 0.82 & 0.122 & 0.84 \\
1.7 & 1.39 & 0.82 & 0.108 & 0.97 \\
3.0 & 2.46 & 0.82 & 0.074 & 0.98 \\
3.6 & 2.95 & 0.82 & 0.068 & 0.98 \\
4.1 & 3.36 & 0.82 & 0.065 & 0.99 \\
\hline
\end{tabular}




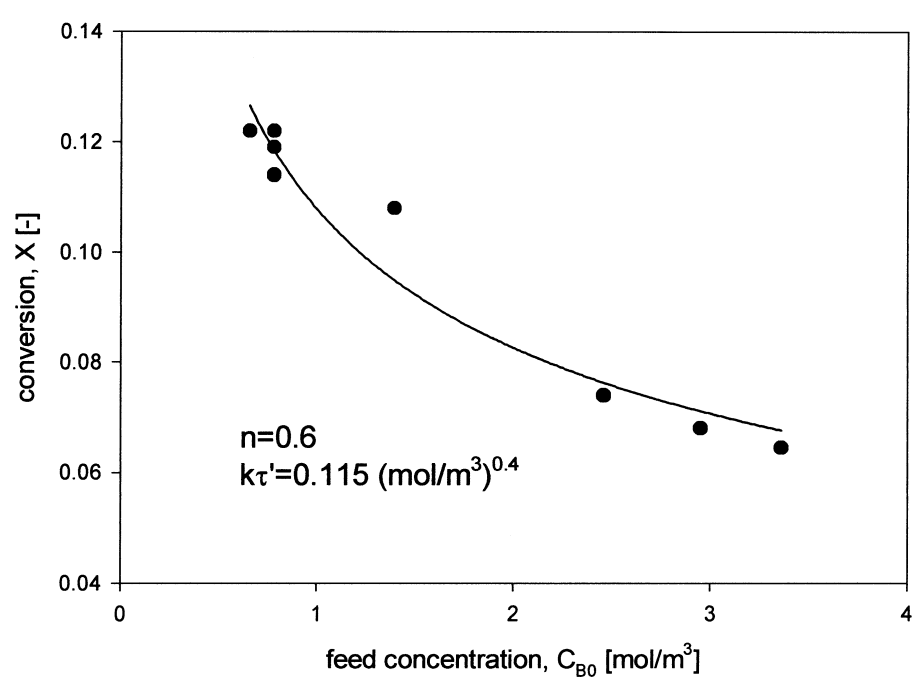

Fig. 4. Dependence of the reaction conversion on benzene concentration in the feed.

of the reaction with respect to benzene. Integration of Eq. (1) for a plug-flow reactor results in:

$X=1-\left(1+(n-1) k \tau^{\prime} C_{\mathrm{B} 0}^{n-1}\right)^{1 /(1-n)}$

where $X$ is the benzene conversion, $C_{\mathrm{B} 0}$ the inlet benzene concentration and $\tau^{\prime}$ defines a modified spacetime which was equal for all experiments: $\tau^{\prime}=$ $696 \mathrm{~kg} \mathrm{~s} \mathrm{~m}^{-3}$. Fitting the experimental data presented in Fig. 4 the rate constant over the structured zeolitic packing was obtained: $k=1.7 \times 10^{-4}$ $\mathrm{mol}^{0.4} \mathrm{~m}^{1.8} \mathrm{~kg}^{-1} \mathrm{~s}^{-1}$.

To compare the performance of the zeolite coatings with the zeolites in traditional fixed-beds, the rate constants were calculated from experimental kinetic data in the same manner as described above, taking the reaction kinetic order $n=0.6$. For the powdered home-made HZSM-5 catalyst a rate constant of $k_{1}=1.0 \times 10^{-4} \mathrm{~mol}^{0.4} \mathrm{~m}^{1.8} \mathrm{~kg}^{-1} \mathrm{~s}^{-1}$ was obtained. The commercial H-MFI-90 gives $k_{1}=$ $1.2 \times 10^{-4} \mathrm{~mol}^{0.4} \mathrm{~m}^{1.8} \mathrm{~kg}^{-1} \mathrm{~s}^{-1}$. In fact, HZSM-5 when used in the form of a structured catalytic packing exhibits a $70 \%$ higher activity compared with its randomly packed form. This higher activity could be explained by the favourable hydrodynamics avoiding flow maldistribution. Nevertheless, improved catalytic performance could also be due to an incorporation of some iron species from the carrier material used. Iron can penetrate into the zeolite matrix during the synthesis of the coatings. This question should be examined carefully.

From the results of Table 1 follows that increasing benzene concentration from 0.66 to $3.36 \mathrm{~mol} \mathrm{~m}^{-3}$ at a constant concentration of nitrous oxide $(0.82 \mathrm{~mol}$ $\mathrm{m}^{-3}$ ) decreases the conversion, but leads to a further improvement in selectivity towards phenol (up to $99 \%$ ). This tendency could be explained by adsorption effects. In fact, an excess of benzene could displace the adsorption-desorption equilibrium between benzene and phenol. Phenol desorption is facilitated reducing the consecutive reactions. Therefore, an aromatic/oxidant ratio and reactant concentrations should be optimised to reach appreciable conversions with $\sim 100 \%$ selectivity. Detailed kinetic studies are in progress in order to optimise the reaction performance.

\section{Conclusions}

Structured catalytic bed made from ZSM-5 coating of stainless steel grids was shown to be active and selective in the phenol formation via partial oxidation of benzene by $\mathrm{N}_{2} \mathrm{O}$. In addition of achieving the same catalytic performance as over zeolites in the traditional fixed-bed (97\% selectivity towards phenol formation at benzene conversion of about $11 \%$ ), these new catalytic packings present several advantages like 
low pressure drop through the catalytic bed, improved heat and mass transfer, and controlled flow hydrodynamics $[1,18]$. These zeolitic packings could be applied also for the end-of-pipe DeNOx $[2,19]$ and other oxidation processes avoiding run-away problems.

\section{Acknowledgements}

The financial support from the Swiss National Science Foundation and the generous supply of zeolite samples by Süd-Chemie are gratefully acknowledged. We also thank M.E. Casali, P. Möckli and B. Senior for technical assistance in catalyst characterisation.

\section{References}

[1] A. Cybulski, J.A. Moulijn, in: Structured Catalysts and Reactors, Marcel Dekker, New York, 1998.

[2] H.P. Calis, A.W. Gerritsen, C.M. van den Bleek, C.H. Legein, J.C. Jansen, H. van Bekkum, Can. J. Chem. Eng. 73 (1995) 120.

[3] H. van Bekkum, E.R. Geus, H.W. Kouwenhoven, Stud. Surf. Sci. Catal. 85 (1994) 509.

[4] M. Iwamoto, J. Hirata, K. Matsukami, S. Kagawa, J. Phys. Chem. 87 (1983) 903

[5] E. Suzuki, K. Nakashiro, Y. Ono, Chem. Lett. 6 (1988) 953.
[6] V. Sobolev, G.I. Panov, A.S. Kharitonov, V.N. Romannikov, A.M. Volodin, K.G. Ione, J. Catal. 139 (1993) 435.

[7] W.F. Hölderich, New frontiers in catalysis, in: Proceedings of the 10th International Congress on Catalysts, Budapest, 1993, 19-24 July 1992, p. 127.

[8] G.I. Panov, A.S. Kharitonov, V.I. Sobolev, Appl. Catal. A: Gen. 98 (1993) 1.

[9] L.M. Kustov, A.L. Tarasov, V.I. Bagdan, A.A. Tyrlov, J. Fulmer, in: Proceedings ISO'99, Rimini (Italy), 1999, p. 131.

[10] J.L. Motz, H. Heinichen, W.F. Hölderich, J. Mol. Catal. A: Chem. 136 (1998) 175.

[11] V. Zholobenko, Mendeleev Commun. (1993) 28.

[12] R. Burch, C. Howitt, Appl. Catal. A: Gen. 86 (1992) 139.

[13] M. Häfele, A. Reitzmann, D. Roppelt, G. Emig, Appl. Catal. A: Gen. 150 (1997) 153.

[14] S. Mintova, V. Valtchev, L. Konstantinov, Zeolites 17 (1996) 462.

[15] V. Valtchev, S. Mintova, Zeolites 15 (1995) 171.

[16] N. van der Puil, F.M. Dautzenberg, H. van Bekkum, J.C. Jansen, Microporous Mater. 27 (1999) 95.

[17] Z. Shan, W.E.J. van Kooten, O.L. Oudshoorn, J.C. Jansen, H. van Bekkum, C.M. van den Bleek, H.P.A. Calis, Microporous Mater. 34 (2000) 81.

[18] J.C. Jansen, W. Nugroho, H. van Bekkum, in: R. von Ballmoos, J.B. Higgins, M.M.J. Treacy (Eds.), Proceedings of 9th International Zeolite Conference, Montreal, 5-10 July, Elsevier, Amsterdam, 1992, p. 247.

[19] J.C. Jansen, J.H. Koegler, H. van Bekkum, H.P.A. Calis, C.M. van den Bleek, F. Kapteijn, J.A. Moulijn, E.R. Geus, N. van der Puil, Microporous Mater. 21 (1998) 213. 